\title{
Standards for skinfold thickness in British newborn infants
}

\author{
J. R. OAKLEY, R. J. PARSONS, AND A. G. L. WHITELAW \\ From the Departments of Paediatrics and Obstetrics, University of Sheffield, and Department of Child \\ Health, Institute of Child Health, London
}

SUMMARY Standards of triceps and subscapular skinfold thicknesses for 1293 Caucasian newborn infants of gestational ages $37-42$ weeks, and of $0.25 \mathrm{~kg}$ birthweight intervals between $2 \cdot 25$ and $4 \cdot 5$ $\mathrm{kg}$ are presented. Female infants had a greater skinfold thickness than males, and the subscapular skinfold was greater than the triceps. The skinfold thickness in both males and females declined after 40 weeks of gestation.

Subcutaneous fat measurements by skinfold calipers have been used for over 20 years in the nutritional assessment of children and adults (Edwards et al., 1955). There are no published standards for newborn infants, though the need for such standards was pointed out by Wagner et al. (1967). We present skinfold thickness centiles for newborn infants of gestational ages $37-42$ weeks, and of $0.25 \mathrm{~kg}$ birthweight intervals between $2 \cdot 25$ and $4.5 \mathrm{~kg}$, using standardized techniques on 1293 infants from three areas of Great Britain.

\section{Patients and methods}

1293 Caucasian, singleton newborn infants of gestational age 37 weeks or more were measured within 48 hours of birth. Babies of diabetic mothers and babies with severe congenital malformations were excluded. Gestational age was assessed from the mother's last menstrual period, unless the mother's dates were in doubt, when gestational age was assessed by ultrasound biparietal diameter early in pregnancy (Campbell and Newman, 1971) and by examination of the newborn (Dubowitz et al., 1970). The left side of the body was used, following the convention of anthropometry over the last 80 years.

746 babies were examined (by J.R.O.) at the Jessop Hospital for Women, Sheffield. 477 babies at Queen Charlotte's Maternity Hospital, London and 70 babies in Scotland at the Simpson Memorial Maternity Pavilion, Edinburgh and the Maternity Hospital, Dunfermline were examined (by
A.G.L.W.). The Harpenden and the Holtain skinfold calipers were used. The two instruments both exert a pressure of $10 \mathrm{~g} / \mathrm{mm}^{2}$ over the whole range of openings but the Holtain caliper was easier to operate in a confined space such as an incubator. The instruments can be read to $0.1 \mathrm{~mm}$ and have small enough surfaces to be used on newborns. Each was zeroed and the calibrations checked using a block measured by a micrometer. During the measurements, the right hand was used to hold the caliper, and the left hand maintained a hold on the skinfold throughout the measurement.

Triceps skinfold was measured over the posterior belly of the triceps muscle of the left arm, half-way between the acromion and the olecranon, on a line passing upwards from the olecranon in the axis of the limb (Tanner and Whitehouse, 1975), with the arm held by the side of the body with the elbow extended. Subscapular skinfold was measured immediately below the angle of the left scapula with the fold either in a vertical line or slightly inclined, in the natural cleavage line of the skin, with the arm by the side of the body (Tanner and Whitehouse, 1975).

Brans et al. (1974) have suggested that calipers should be left on the skinfold of the newborn for 60 seconds because otherwise the presence of oedema in the neonate gives a falsely high estimate of subcutaneous fat. We agree with the suggestion that the skinfold reading after 60 seconds' pressure represents subcutaneous fat, but in practice it is only necessary to leave the caliper on until the reading is stable. In most of the term babies this was long before 60 seconds, though in some low birthweight babies the skinfold reading continued to 
decline until almost 60 seconds. It was rare for a baby to be upset by the skinfold measurements. Examining the babies in the mother's or nurse's arms and allowing the baby to suck on a teat or a freshly washed finger was very effective in pacifying them. The frequency distributions of the skinfold thicknesses within each gestational age and $0.25 \mathrm{~kg}$ birthweight class intervals were not significantly different from gaussian and so the measurements were analysed without logarithmic transformation. This is in agreement with Farr (1966).

Because girls have fatter skinfolds than boys, results for males and females were analysed separately.

\section{Reproducibility}

Duplicate skinfold measurements made one hour apart by a single observer gave $95 \%$ confidence limits at the triceps site of $\pm 4.6 \%$ of the mean triceps skinfold, at the subscapular site of $\pm 2.5 \%$ of the mean subscapular skinfold, and of $\pm 2.5 \%$ of the mean skinfold for the average of the two sites. When both observers (A.G.L.W. and J.R.O.) measured the same babies, the difference between the two observers' readings was never more than $0.3 \mathrm{~mm}$.

\section{Results}

Table 1 shows the number of male and female infants in each week of gestation, and Table 2 the number in each $0.25 \mathrm{~kg}$ birthweight interval. There are 669 males and 624 females.

Table 1 Distribution of male and female infants by gestational age

\begin{tabular}{llllllll}
\hline $\begin{array}{l}\text { Gestational } \\
\text { age }(w)\end{array}$ & 37 & 38 & 39 & 40 & 41 & 42 & Total \\
\hline Male & 49 & 86 & 128 & 252 & 109 & 45 & 669 \\
Female & 34 & 73 & 123 & 242 & 118 & 34 & 624 \\
\hline
\end{tabular}

Figs. 1, 2 show the unsmoothed centile lines of the triceps and subscapular skinfold thicknesses for males and females by gestational age, indicating a greater skinfold in females at each week of gestation. In both sexes the subscapular skinfold thickness is greater than the triceps. In each figure the skinfold thickness declines after $\mathbf{4 0}$ weeks of gestation.

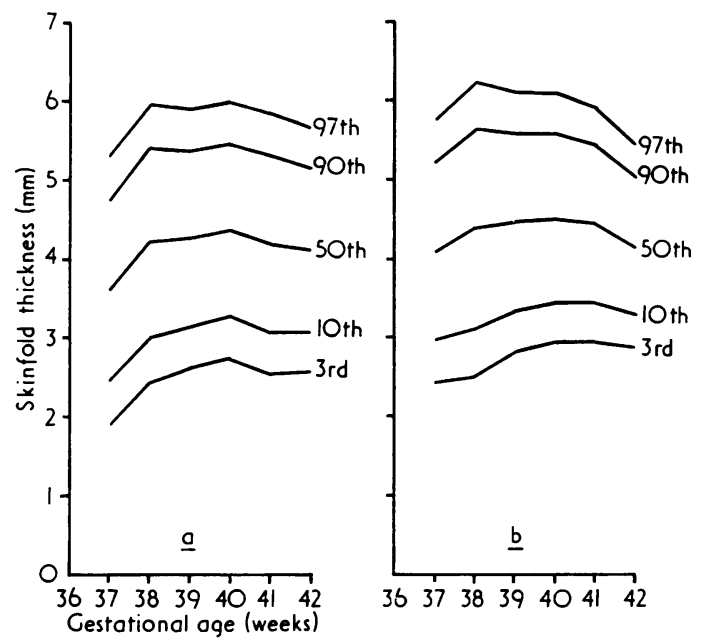

Fig. 1 Variation of triceps skinfold thickness with gestational age for (a) males (b) females.

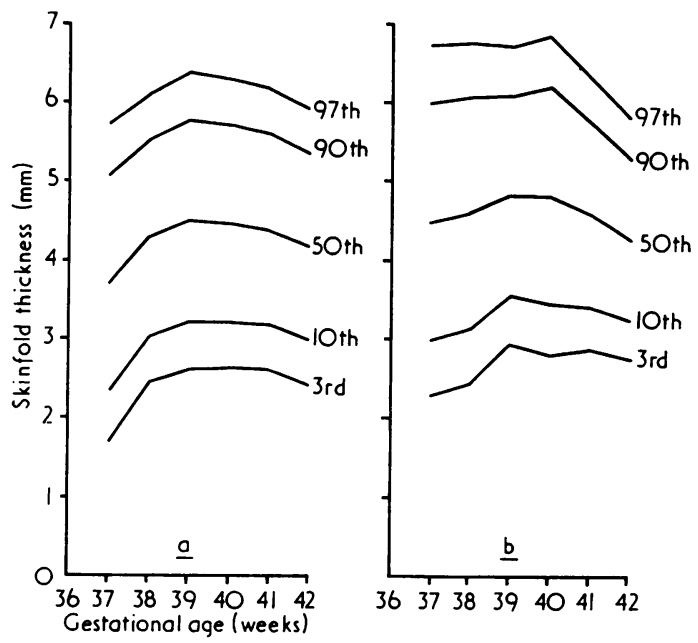

Fig. 2 Variation of subscapular skinfold thickness with gestational age for (a) males (b) females.

Figs. 3, 4 show the unsmoothed centile lines of triceps and subscapular skinfold thickness for males and females, by $0.25 \mathrm{~kg}$ birthweight class intervals. Within each birthweight interval female infants have a greater skinfold thickness than males.

Table 2 Distribution of male and female infants by birthweight intervals of $0.25 \mathrm{~kg}$

\begin{tabular}{|c|c|c|c|c|c|c|c|c|c|c|c|c|}
\hline $\begin{array}{l}\text { Weight } \\
\text { interval }(k g)\end{array}$ & $<2 \cdot 24$ & $2 \cdot 25-2 \cdot 49$ & $2 \cdot 5-2 \cdot 74$ & $2 \cdot 75-2 \cdot 99$ & $3 \cdot 0-3 \cdot 24$ & $3 \cdot 25-3 \cdot 49$ & $3 \cdot 5-3 \cdot 74$ & $3 \cdot 75-3 \cdot 99$ & $4 \cdot 0-4 \cdot 24$ & $4 \cdot 25-4 \cdot 49$ & $>4 \cdot 5$ & Total \\
\hline $\begin{array}{l}\text { Male } \\
\text { Female }\end{array}$ & $\begin{array}{l}20 \\
12\end{array}$ & $\begin{array}{l}15 \\
21\end{array}$ & $\begin{array}{l}43 \\
48\end{array}$ & $\begin{array}{l}66 \\
66\end{array}$ & $\begin{array}{l}116 \\
144\end{array}$ & $\begin{array}{l}131 \\
119\end{array}$ & $\begin{array}{l}128 \\
105\end{array}$ & $\begin{array}{l}81 \\
53\end{array}$ & $\begin{array}{l}41 \\
33\end{array}$ & $\begin{array}{l}16 \\
16\end{array}$ & $\begin{array}{r}12 \\
7\end{array}$ & $\begin{array}{l}669 \\
624\end{array}$ \\
\hline
\end{tabular}



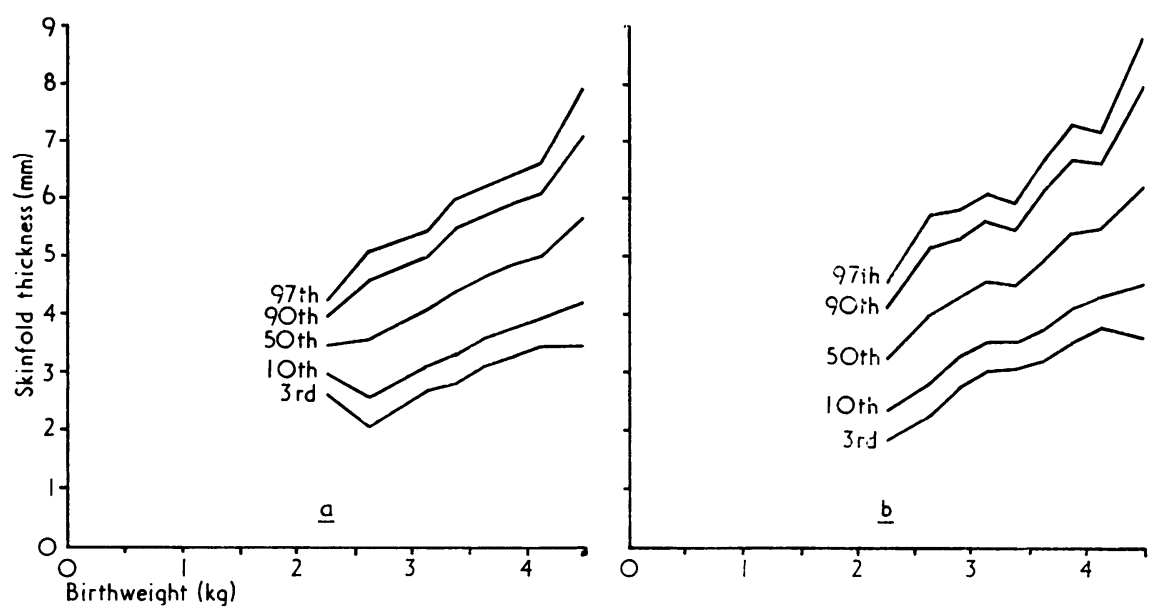

Fig. 3 Variation of subscapular skinfold thickness with birthweight for (a) males (b) females.
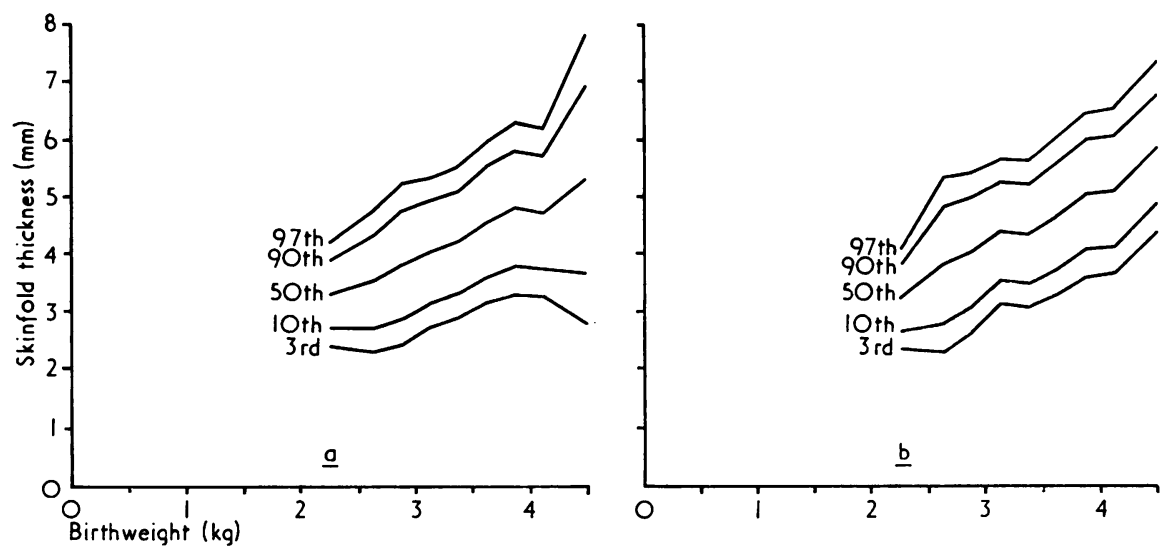

Fig. 4 Variation of triceps skinfold thickness with birthweight for (a) males (b) females.

\section{Discussion}

These centiles are derived from Caucasian babies in three areas of Great Britain. They do not necessarily apply to non-Caucasian infants. The findings that female newborns have a greater skinfold thickness than males, and that the subscapular skinfold is greater than the triceps skinfold in term babies agree with Gampel (1965) and Farr (1966). The decline in skinfold thickness after 40 weeks' gestation may indicate aging of the placenta and the beginning of failing nutrition to the fetus.

The skinfold centiles are presented because we believe that variations in subcutaneous fat are of clinical significance in neonatology and that they shed light on fetal and neonatal nutrition. Bodyweight does not necessarily indicate the amount of body fat as individual babies may be heavy without being fat if they are large, have heavy bones, big muscles, large heads, or water retention. It has become increasingly recognized that not all babies below the 10th centile for birthweight are suffering from undernutrition. Ounsted and Ounsted (1971) have pointed out that some small-for-dates babies are not thin but are constitutionally small or 'miniatures'. The finding of reduced subcutaneous fat for gestational age, or when this is uncertain, for birthweight, may help to distinguish the truly undernourished thin-for-dates baby at risk of hypoglycaemia from the constitutionally small neonate.

Oakley and Parsons (1976) have shown that some term infants with birthweights of more than $2.5 \mathrm{~kg}$ may have plasma glucose levels at 4 hours of age 
which are less than $1.1 \mathrm{mmol} / 1(20 \mathrm{mg} / 100 \mathrm{ml})$ and that skinfold thickness (standard deviation score for birthweight) has a highly significant positive correlation with plasma glucose at 4 hours of age.

Whitelaw (1976) has shown that maternal obesity is associated with increased skinfold thickness in the baby, and that prolonged maternal hypertension is associated with reduced skinfold thickness in the baby. In diabetic pregnancy excessive subcutaneous fat in the neonate may be an indication of inadequate control of maternal diabetes (Whitelaw, 1977).

Skinfold thickness measurement is noninvasive, cheap, and reproducible. These centiles may assist the standardization of further investigation into perinatal nutrition.

We are grateful to Professors June K. Lloyd, R. D. G. Milner, and O. H. Wolff for their interest, encouragement, and help in this study; to Mrs J. Verrier for help with data processing; and to all the consultants whose patients comprise this study.

\section{References}

Brans, Y. W., Sumners, J. E., Dweck, H. S., and Cassady, G. (1974). A non-invasive approach to body composition in the neonate. Dynamic skinfold measurements. Pediatric Research, 8, 215-222.

Campbell, S., and Newman, G. B. (1971). Growth of the fetal biparietal diameter during normal pregnancy. Journal of Obstetrics and Gynaecology of the British Commonwealth, 78, 513-519.
Dubowitz, L. M. A., Dubowitz, V., and Goldberg, C. (1970). Clinical assessment of gestational age in the newborn infant. Journal of Pediatrics, 77, 1-10.

Edwards, D. A. W., Hammond, W. H., Healy, M. J. R., Tanner, J. M., and Whitehouse, R. H. (1955). Design and accuracy of calipers for measuring subcutaneous tissue thickness. British Journal of Nutrition, 9, 133-143.

Farr, V. (1966). Skinfold thickness as an indication of maturity in the newborn. Archives of Disease in Childhood, 41, 301-308.

Gampel, B. (1965). Relation of skinfold thickness in the neonate to sex, size at birth, length of gestation and maternal skinfold. Human Biology, 37, 29-37.

Oakley, J. R., and Parsons, R. J. (1976). Skinfold thickness as indicator of neonatal hypoglycaemia in infants of greater than $2.5 \mathrm{~kg}$ birthweight. Paper presented to Neonatal Society meeting in Birmingham, July 1976.

Ounsted, M., and Ounsted, C. (1971). On Fetal Growth Rate. Clinics in Developmental Medicine No. 46. Heinemann, London.

Tanner, J. M., and Whitehouse, R. H. (1975). Revised standards for triceps and subscapular skinfolds in British children. Archives of Disease in Childhood, 50, 142-145.

Wagner, M., Wagner, G., and Mathis, R. (1967). Measurements of nutritional status of newborn infants. Biology of the Neonate, 11, 106-114.

Whitelaw, A. G. L. (1976). Influence of maternal obesity on subcutaneous fat in the newborn. British Medical Journal, 1, 985-986.

Whitelaw, A. (1977). Subcutaneous fat in newborn infants of diabetic mothers: an indication of quality of diabetic control. Lancet, 1, 15-18.

Correspondence to Dr A. G. L. Whitelaw, Special Care Baby Unit, Northwick Park Hospital, Harrow, Middlesex HA1 3UJ. 